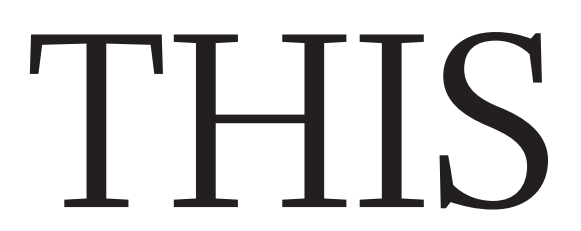

EDITORIALS
WORLD VIEW The first steps on the slippery slope to academic fraud $\mathbf{p . 1 5 1}$

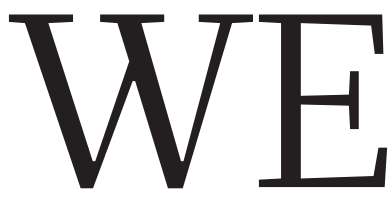

GRAVITY GRAVE Blackhole survey puts down minimum size marker $\mathbf{p} .152$
FosSIL Old bone shows ancient beaked whales had skeletal worms p.153

\title{
Academic freedom
}

\section{A court decision in the United States rescinding an order to turn over academic e-mails in response to a freedom-of-information request is welcome.}

S cottish law exempts academic work from the freedom-ofinformation laws, but the rest of the United Kingdom does not. Ireland also exempts, and although the United States is commonly thought to, it turns out that, as so often in that country, it is left to the courts to decide. So, just what should researchers make of freedom-of-information laws?

American climatologist Michael Mann, now at Pennsylvania State University in University Park, probably knows the score better than most. And in the latest twist in a long-running saga over who should be able to read Mann's e-mails, a Prince William County Circuit Court judge in Manassas, Virginia, last week tore up an agreement that would have given the e-mails, with conditions, to attorneys for the American Tradition Institute (ATI), a conservative think tank. Judge Gaylord Finch also granted Mann's request to join the University of Virginia (his former employer and holder of the e-mails) in a lawsuit to block their release.

As both sides argue about whether the messages should ultimately be made public, the two legal decisions come as welcome news to those (including this journal) who believe that access to personal correspondence is a freedom too far. But the case highlights, yet again, how woefully unprepared the academic community is to meet this kind of challenge. This must change.

Certainly, the University of Virginia caved in too easily when it signed the agreement that granted the ATI access to the e-mails last spring. Given the tone of public statements that have come out of the ATI, the university should never have agreed to hand over confidential material of any sort.

But the university and its attorneys deserve credit for rectifying the situation. And despite appearances, to fight such requests is not against the letter, or indeed the spirit, of perfectly proper regulations designed to improve the accountability of public bodies. In fact, Virginia's freedom-of-information law provides the university with a solid basis to deny access to this kind of blanket request for e-mail records: academic work is exempt. This is as it should be, and the university should fight to protect that exemption now and in the future.

Yes, the public has a right to know, and yes, greater scrutiny of public spending is a good thing. But research practice is typically protected for good reasons too. To protect academic freedom is a foundation for intellectual property and copyright laws, while in court, both Mann and the university warned of the chilling effect of such demands on communication between scientists. Certainly, many researchers are more wary of e-mail today, and given Mann's experiences, who can blame them?

His case is high profile, but scientists and academics watching it (as well as the related attempts by Virginia's attorney-general Ken Cuccinelli to force the release of the same e-mails) should be cautious about drawing broad conclusions from how it may pan out. Even within the United States, the eventual ruling won't serve as much of a precedent outside Virginia. Federal agencies in the United States are subject to the federal statute, but state universities and research institutions must all play by the laws enacted in their own states.

Across those states it seems that this kind of academic exemption is
"Access to

personal correspondence

is a freedom too far." common, but not universal, and its application would vary according to precedents set locally. In other words, it will be up to individual universities to work out how to address these kinds of cases as they emerge in future.

Mann's decision to join the lawsuit was spurred by the initial decision of the university to grant ATI access to his e-mails, a move with which he disagreed. He suggests that universities may be limited in what they can do to fend off these attacks, or that their interests may not always align precisely with those of individual researchers.

Mann is also getting help from a new fund especially designed to aid climate scientists hit by legal challenges, and organizations including the American Geophysical Union, the American Association of University Professors and the Union of Concerned Scientists have weighed in as well. All of this is good and useful, but it is no substitute for a solid institutional defence. Individual universities and research institutions everywhere should review their own policies and make sure they know the applicable laws as well as do those who would use them for mischief, or worse.

\section{Innovative vision}

\section{Bill Gates gave the G20 summit a workable plan to boost development around the world.}

W hat a shame that the latest lurch of the financial crisis in Greece and the eurozone overshadowed all else at last week's G20 summit in Cannes, France. For on the agenda was a brief but important report on ways to boost funding for development, research and innovation in health and agriculture. If implemented, its suggestions would stimulate innovation and go a long way towards helping to alleviate poverty, hunger and disease. The report came from computertycoon-turned-philanthropist Bill Gates, and although the typically vague final G20 communiqué gave his suggestions only brief mention, that they feature at all in the current climate is a notable achievement.

Gates, the first private individual to address a G20 summit, pleaded for countries not to let the financial crisis cause them to renege on their existing pledges, which would generate an additional US $\$ 80$ billion annually from 2015 onwards. 
Some programmes, such as the GAVI Alliance - formerly the Global Alliance for Vaccines and Immunisation — have seen pledges increase this year (see go.nature.com/qlldf4), and donors must follow through with the cash. Others have not been so lucky. Donations to the Global Fund to Fight AIDS, Tuberculosis and Malaria, for example, last year fell far short of its funding target (see Nature 467, 767; 2010). And the comprehensive Global Funding of Innovation for Neglected Diseases (G-Finder) report, due next month, is expected to say that most donors slashed funding for neglected-disease research and development last year - causing an overall fall of more than $\$ 100$ million, or more than $5 \%$. The risk is that the financial crisis could roll back the huge progress that has been made in both funding and outcomes for global health and research since neglected diseases returned to the international agenda in the mid-1990s - and also stymie a recent resurgence of interest in agricultural research and development (R\&D) for developing nations.

To combat this threat, Gates rightly emphasized the urgent need for new funding mechanisms to boost development and make it less vulnerable to financial turmoil. And he made a compelling case for measures that, between them, could potentially raise more than $\$ 100$ billion a year. Gates also put his finger on a key point: cash flow between rich and poor countries is not a one-way street of aid from donors to recipients. Many poorer nations have substantial natural resources, the revenues from which exceed that of aid. Yet countries are sometimes given raw deals by foreign companies exploiting those resources, and revenues can also end up in the bank accounts of corrupt public officials. The result is a haemorrhaging of financial resources, some of which could otherwise be spent on building labs, hospitals and sanitation systems, training researchers and doctors, or buying bed nets and drugs.

To tackle this, Gates called on the G20 countries to embrace the Extractive Industries Transparency Initiative (EITI), a World Bankbacked scheme, launched in 2002, to oblige companies and countries to make public the terms of oil, gas and mineral deals in order to better

monitor both whether the deals are fair and where that money goes. The sums involved are potential game changers that could also transform neglected diseases and agricultural R\&D. Gates points out that, at peak production, Uganda's oil reserves are estimated to generate $\$ 2$ billion annually, which is almost as much as the country's entire national budget of $\$ 3$ billion. However, the confidentiality of the terms of deals with firms makes it impossible to track either whether countries are

"Cashflow poor countries is not a one-way street." between rich and getting good deals, or where all the cash goes.

The EITI is gaining traction, and teeth, with US President Barack Obama announcing in September that the United States would adopt legislation to make it EITI compliant, and the European Union is considering following suit. But Gates is right to call on all G20 countries to endorse the EITI, and to force companies listed on their stock exchanges to disclose the royalties they pay to governments - and for that measure to be extended to resources such as land and timber.

Gates also called for a share of sovereign wealth funds to be invested in infrastructure, and lent his support to proposals for a small tax on tobacco and financial transactions, and a carbon tax on aviation and shipping fuel, which together could raise at least tens of billions of dollars. Financial-transaction taxes already exist in several countries, and, as Gates said, "are clearly technically feasible". Likewise, UNITAID, an international organization that helps to accelerate development and scale-up of access to treatments for HIV and AIDS, malaria and tuberculosis, is largely financed by an airline tax paid by its member states.

Gates deserves great credit for highlighting these issues and helping to keep them on the international agenda. Research leaders and politicians must press for them to remain there, and for action to follow. It would be a fitting result if the man whose operating systems forced the world to learn the keyboard sequence CTRL-ALT-DEL can spark a much-needed reboot of funding of research for development.

\section{Hubble cleared}

\section{A painstaking study absolves US astronomer Edwin Hubble of censoring a Belgian rival.}

\footnotetext{
$\mathrm{E}$
} dwin Hubble is that relatively rare thing among dead astronomers - a global household name. He owes his status mainly to the NASA space telescope named in his honour. So when researchers suggested this year that Hubble might have censored the work of a rival to secure credit for the groundbreaking discovery that the Universe is expanding, they triggered a fuss that was far removed from the usual arcane wrangling over historical research priority.

In an admirably thorough Comment on page 171, Mario Livio, an astronomer at the Space Telescope Science Institute in Baltimore, Maryland, clears Hubble of wrongdoing. As a result, NASA and a generation of researchers whose careers are closely tied to the Hubble brand can look skywards with some relief.

The charges against Hubble certainly warranted examination. In 1927, the Belgian astronomer Georges Lemaitre published a Frenchlanguage paper in the Annales de la Société Scientifique de Bruxelles that laid out the essentials of a picture of galaxies expanding away from one another, and derived an expansion parameter on the basis of then-recent observations. In 1929, Hubble independently put forward and confirmed the same idea, and the parameter later became known as the Hubble constant. In 1931, Lemaître's paper was translated into English and published in the Monthly Notices of the Royal Astronomical Society, but most English speakers probably learned of Hubble's contribution before they learned of Lemaître's.

Suspicions of foul play emerged earlier this year, when amateur historians noticed that the derivation of the expansion constant is missing from the English translation of Lemaitre's work. Knowing that Hubble was concerned that he, and the Mount Wilson Observatory in Pasadena, California, at which he made his observations, should get ample credit for confirming the expansion of the Universe, it was tempting to speculate that he had a hand in the editing of the Belgian's paper. But motive alone doesn't build a case, and professional historians, who had known of the irregularity for years, remained sceptical.

Livio's research suggests that they were right to hesitate. After reviewing hundreds of documents in the archives of the Royal Astronomical Society in London, Livio found a copy of a 1931 letter by Lemaitre in which he said that in translating his paper, he had deleted discussion of the velocities of galaxies because it was "of no actual interest". Why exactly Lemaître thought this is unclear, but it seems that he was not very concerned about getting the credit for his work in the way that modern followers have assumed; instead, he may have worried more about seeming out of date, given that the data on which the expansion constant was based had been improved since 1927.

The idea that the accuracy of papers and their relevance to colleagues ought to be more important than ensuring priority at every step may seem fantastic in today's cut-throat world of science. And perhaps it was then, too. Perhaps Lemaitre was simply so flattered to be invited to translate his paper that, aware of Hubble's importance among English-speakers and fearful of repercussions, or eager to join the Royal Astronomical Society, he self-censored. The case against Hubble is closed, but there may still be a story for motivated historians to look into.

Space agencies should also take note. Whether or not Hubble deliberately censored Lemaitre, the fact is that in the $\rightarrow$ NATURE.COM To comment online, click on Editorials at: go.nature.com/xhunqv English-speaking world, Lemaitre has lost - to Hubble - priority for his contributions. The Belgian's name is a worthy candidate for the title of a future space mission.. 